\title{
Notas para um pensamento por imagem: do discurso visual à imagem como queda
}

\author{
Anelise Angeli de Carli \\ Ana Taís Martins Portanova Barros \\ Universidade Federal do Rio Grande do Sul
}

\begin{abstract}
Resumo
No presente artigo, apresentamos uma reflexão sobre a noção de imagem a partir da fotografia que ficou conhecida como The Falling Man, feita durante o atentado de 11 de setembro de 2001 em Nova lorque. Essa discussão toma o sistema do imaginário antropológico como uma perspectiva embasadora dos questionamentos acerca da existência de um pensamento por imagem. O texto inicia explorando o alcance da perspectiva do discurso visual e os limites de se tomar a imagem como argumento e chega a apontar para a necessidade de adicionar elementos da teoria da imagem à discussão no caso de fotografias que venham a se tornam elas mesmas um acontecimento.
\end{abstract}

\section{Palavras-chave:}

Imagem. Imaginário. Imaginação simbólica. Fotografia. Experiência estética.

\section{Da imagem como argumento}

Tomar a imagem como argumento ou como signo é operação próxima daquela proposta pelas teorias do dispositivo que sugerem a ideia de discurso visual para o estudo da fotografia (PICADO, 2003, 2009; SANTOS, 2009). A perspectiva propõe adicionar ao pensamento da comunicação, "predominantemente semiótico, em sua história" (PICADO, 2003, p. 203), a contribuições vindas das teorias da representação pictórica ${ }^{1}$.

Para superar a noção atestatória da fotografia, dá-se necessário destaque à ativação de um código icônico, isto é, um quadro de referência comum que torna possível a identificação de objetos representados com o modo como os enxergamos na nossa experiência da realidade imediata. O estatuto indicial da fotografia - tão caro ao fotojornalismo - só se daria em um momento posterior ontologicamente, dado que é situação decorrente de um prévio compartilhamento de quadros de referência mínimos. Um deles é a perspectiva artificialis ${ }^{2}$, que garante

1 O ponto de virada do argumento está em superar, em fotografia, a colagem da representação visual com a referência, um entendimento que Alloa (2015) chama de teoria da transparência, utilizando-se da concepção de Danto para a história da arte.

2 Sistematizada por Leo Batista Alberti em 1443, descrevia, entre outras coisas, o sistema geométrico utilizado pelas obras dimensionais como a pintura e o desenho para criarem a ilusão da profundidade e da proporção dos volumes (MACHADO, 2015). Objetivas com distância focal média

\section{Revista Ícone (ISSN 2175-215X)}

Recife, Vol. 16, N. 2, 225-239, ๔ 2018 PPGCOM/UFPE.

Artigo recebido em 31 ago. 2018 e aprovado em 22 set. 2018.

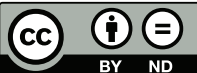


à representação visual bidimensional aproximar-se dos defeitos de observação do olho humano. É evidente que esta experiência de realidade não é refém de nenhuma idéia de realismo, podendo, pois, o fotógrafo se utilizar de recursos pouco fidedignos à maneira tradicional de ver dos olhos, sugerindo efeitos de enquadramento e angulação que distorçam a perspectiva e, assim, encontrar "uma organização intencional dos componentes da imagem" que julgue mais "adequada" (SANTOS, 2009, p. 119) ou que provoquem outras experiências de mundo - e, portanto, de sentido ${ }^{3}$.

Para ilustrar o modo de pensar o fotojornalismo sob a perspectiva do discurso visual, Santos (2009) retoma o conhecido retrato de Jânio Quadros com os pés tortos ${ }^{4}$. A foto foi "apropriada discursivamente para definir a personalidade do político e simbolizar uma falta de rumos que lhe marcava a atuação política" (SANTOS, 2009, p. 127). Isto é, a fotografia funcionou no contexto da notícia porque convinha a seu conteúdo. De alguma forma seu aspecto visual afinava com a ideia já posta em causa: Jânio é inadequado. Outra fotografia que mostrasse um presidente desenvolto, altivo, não serviria para acompanhar tal construção discursiva.

É da mesma maneira que opera o exemplo de Picado (2006), ao relembrar o retrato de Trotsky, tomado por um gestual magnânimo e audacioso, primeira fotografia publicada de Robert Capa. Escolhida dentre uma série de possíveis no copião, a foto publicada é a que se destaca pois pode melhor "servir de apoio visual" ou, ainda, atender "à finalidade de reforço do discurso reportativo" (PICADO, 2006, p. 162-163). Os outros retratos do copião não coincidem com a imagem de Trotsky a qual se quer reportar. Esse jogo discursivo é próprio da lógica do discurso verbal que tema intenção de conferir coerência à narrativa.

Contudo, Picado (2006, p. 163) alerta que "o efeito de discurso próprio das imagens" não se restringe aos oferecidos pelos estudos dos critérios e modos de funcionamento do jornalismo. A mobilização de propriedades visuais específicas indicia a presença de um sujeito que atua, através da mobilização de códigos visuais compartilhados, em prol da elaboração de uma imagem visual que transmita sentido, ou seja, promova a criação de um discurso ${ }^{5}$. No caso do fotojornalismo, é conveniente que este discurso visual, criado iconicamente, tenha efeito indicial.

O discurso visual é uma perspectiva presente no estudo das artes visuais e também da fotografia. O sufixo se deve ao fato de que, antes de servir para a discussão dos temas da arte, o discurso aparece como noção da filosofia da linguagem. Já que mobiliza a necessária intervenção de um cogito que operacionaliza o código icônico, a ideia de representação (que está na gênese da "imagem" à qual se refere o discurso visual) está ligada, também, a uma noção de sujeito ativo que escolhe e mobiliza os elementos para remontar e dar significado à cena. $\mathrm{O}$ discurso

de 50mm apresentam uma distorção da perspectiva muito parecida à do olho humano, criando a impressão do espaço topográfico baseado em linhas paralelas e perpendiculares.

3 Esta era a tese sustentava por Rochtchenko ao propor uma quebra do espaço topológico (DUBOIS, 2012) em suas fotografias do cotidiano soviético (MACHADO, 2015).

4 Fotografia de Erno Schneider, publicada pelo Jornal do Brasil em 1961.

5 A palavra discurso tem por vezes seu significado erroneamente restringido ao campo da produção verbal. No entanto, discurso concerne qualquer movimento que organiza o sentido - ou, mais precisamente, a significação - a partir de plataformas diversas como a "linguística, icônica, audiovisual, gestual etc." (CHARAUDEAU, 2006, p. 10). 
visual não é, reiterando, uma maneira de subjugar a fotografia ao regime linguístico (SANTOS, 2009), mas de dar a ela os mesmos poderes de enunciação.

As reflexões do discurso parecem recorrer em suas proposições a um conceito próprio da semiótica peirceana, a tríade sígnica, que é responsável por conduzir a uma operação lógica de significação. Peirce (1990, p. 11) defende que os fenômenos são percebidos através de uma "conexão tripla de signo, coisa significada, cognição produzida na mente", considerando que o mundo existente é composto somente daquilo que está disponível à nossa consciência através dos signos, e que podem afetar a mente. Na lógica peirceana, a imagem, por mais que organize o pensamento e seja uma zona incerta de intensidades, somente estaria acessível através de sua condição de representamen, a condição material do pensamento. Quer dizer, por mais que haja uma consideração a respeito da imagem como algo que escapa das categorias, só interessa à semiótica - só é cognoscível - aquilo que se integra ao percurso da semiotização. As categorias triádicas do pensamento peirceano funcionam quando, então, a imagem já é sinônimo de símbolo. É a partir desta ontologia da imagem que se desenvolve a perspectiva do discurso visual: matrizes arbitrárias de sentido que mobilizam diferentes tipos de imagem em diversas plataformas cujas combinações e intertextualidades produzem discursos.

Picado (2003, p. 203) aponta para a importância de desenvolver uma metodologia de "análise dos materiais visuais" que não cometa o descuido de fazer o discurso visual se submeter ao "regime das conotações". Acionando o freio, contudo, frente às possibilidades da metafísica, em nota de rodapé, explica que o problema se bifurca ora na "perspectiva das semióticas", que aposta "numa espécie de vínculo gramatical entre os ícones e seus significados", ou numa "visão perceptualista" que compromete a análise das imagens ao fazer relacionarem-se a "compreensão das imagens visuais e as estruturas perceptivas de base" (PICADO, 2003, p. 217-218).

\section{O sublime na fronteira do discurso}

Vamos agora dimensionar alguns motivos que explicam o funcionamento das representações e a sua chegada ao sublime. Nas palavras de Picado (2009, p. 144), o fotojornalismo funciona graças a uma "estabilidade da representação". Na sua concepção, os aspectos que relacionariam uma fotografia em termos de semelhança a um acontecimento interessariam menos do que os vínculos indexicais que certas formas estabelecem com uma ordem de sentido que já conhecemos. Além do caso da distorção perspectiva que já comentamos, a relação indexical pode se dar de maneira mais alargada, por exemplo, baseada na nossa experiência passada: metais retorcidos e edifícios abaixo "conotam a força destruidora" que seria capaz de provocar essa destruição (PICADO, 2009, p. 144). Esse é um índice mediado não somente pelo vínculo icônico, mas pelo indício do conhecimento prévio que compartilhamos.

Mas, ora, se somos capazes de dotar de sentido algo que vemos a partir desses vínculos indexicais prévios (via experiência empírica ou conhecimento de conceitos) e se a perspectiva do discurso visual se baseia no compartilhamento de quadros de referência que, por sua vez, se valem de certa estabilidade da representação, nos parece pertinente indagar se há momentos em que o sentido escapa do previsto. Este momento, adianta Picado (2009) existe, e se trata da "sublimidade", que acontece quando a imagem evoca algo impossível de representar.

Uma das formas de compartilhar um sentido, quando estamos pensando em fotografias 
de imprensa, é o descrito por Charadeau (2006, p. 4) como "imagem-sintoma": "uma imagem ‘já vista' (...) que [nos] reenvia a outras imagens”. Esse déjà vu, segundo ele, se deve a certa "analogia formal" e certo "discurso verbal interposto" (CHARADEAU, 2006, 2009) - formas de significação bastante próximas às que animam a ideia de estabilidade de representação. Uma imagem visual se relaciona com outras representações visuais semelhantes através do aspecto memorial das formas. Além disso, segundo o semiolinguista, uma imagem visual terá efeito de “já vista” se ela estiver de algum modo relacionada a outros discursos ${ }^{6}$ que já conhecemos sobre o mesmo tema. Nas palavras do autor, essa junção de sentidos é própria de um "acontecimento dramático", quando "verdades de opinião" se fundem a "verdades de emoção"; e é dessa relação que estão povoados nossos “imaginários? sociais” (CHARAUDEAU, 2009, p. 83).

Não à toa, a relação entre o já visto e o sublime aparece constantemente na imprensa, nas vezes em que o jornalismo conta a história de uma tragédia produzindo fotografias que parecem pinturas, depoimentos emocionados que por vezes dão origem a documentários sobre o sentido da vida e a fragilidade humana. A força dramática do acontecimento faz com que o evento escape do relato do cotidiano e alcance estatuto de crônica.

Quando Charaudeau $(2006,2009)$ enfatiza esse processo de significação da imagem através de uma via dupla (semelhança formal e semiótica), mobiliza o valor referencial da imagem. O valor discursivo de uma imagem depende das intertextualidades nas quais sua significação é construída, ou seja, de uma série de discursos que a sustentem como simbolicamente consistentes (CHARADEAU, 2006, 2009). As imagens visuais presentes no discurso jornalístico teriam mais um caráter de testemunho do que de metáfora e vêm sempre acompanhadas de depoimentos, dados e averiguações. Na encenação televisiva, para a criação de uma narrativa visual, jornalistas justapõem personagens, informações, cenários, cenas de arquivo, e é desta maneira, segundo Charaudeau (2009), que mesmo a imagem-sintoma também é utilizada como argumento.

Este funcionamento da imagem como argumento de outra coisa, evidencia uma segunda camada operante de sentido que coloca a imagem a serviço de outra coisa. Na elaboração de uma reportagem televisiva ou de uma fotorreportagem, há um necessário trabalho de elaboração da narrativa visual que coloca em xeque a justaposição de imagens e textos tentando

6 Estamos tomando a noção de discurso que o compreende como um fenômeno que acontece não na plataforma enunciativa, mas através dela. Como bem expôs Benetti (2008, p. 17), a partir da concepção de Charaudeau e da Análise do Discurso francesa, o discurso - e também o discurso jornalístico - "acontece entre os sujeitos da interlocução", que têm seu poder de enunciação condicionado ao conhecimento das regras de funcionamento do discurso e do compartilhamento de quadros de referência.

7 Neste texto, Charaudeau (2009) não se refere a nenhuma teoria específica do imaginário a qual esteja se reportando, o que nos leva a crer que esteja mencionando o termo somente para retomar seu significado coloquial, como constructo mental compartilhado socialmente. A queda das Torres Gêmeas, segundo ele, conduz a uma "analogia mais abstrata" (2006, p. 5), como ao "desmoronamento (...) do progresso humano" $(2009$, p. 83). Mas o que nos leva a relacionar o desmoronamento de uma torre à queda de um projeto de humanidade? Por que a imagem da queda se relaciona a uma ideia de decadência? Por mais que possuam forte entrelaçamento simbólico, essas não são relações de sentido cujas motivações são dadas e evidentes. Não são questões debatidas por Charaudeau $(2006,2009)$, mas são perguntas próprias da investigação conduzida pela teoria geral do imaginário de Gilbert Durand (1997). 


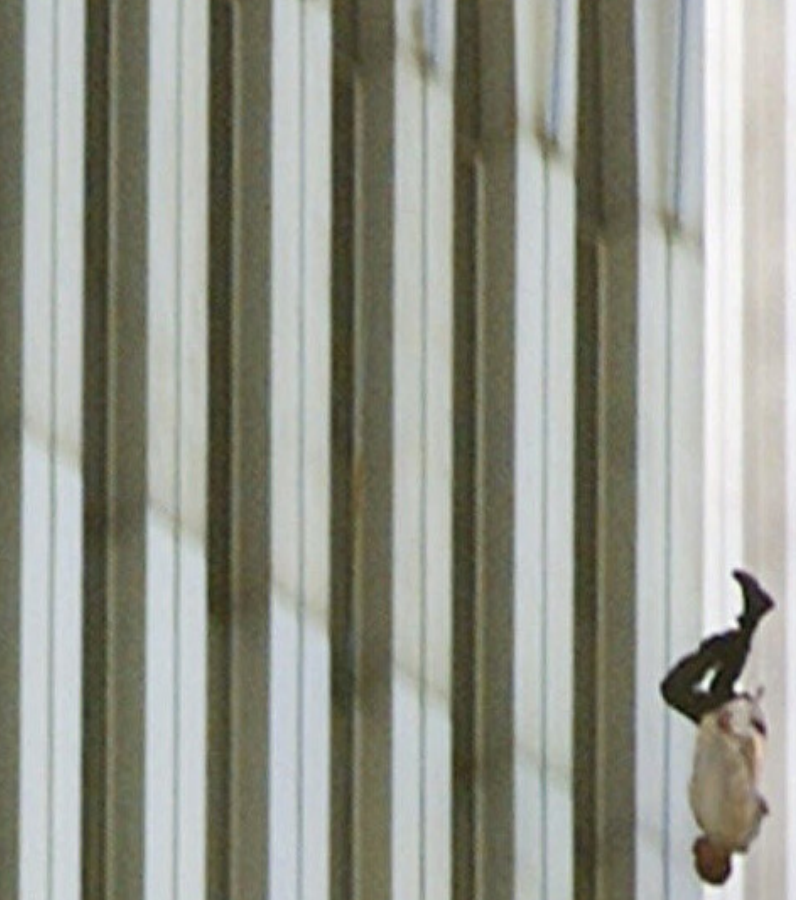

Figura 1-The Falling Man. Richard Drew/Associated Press, 2001. 
prever possíveis efeitos de sentido e intertextualidades. Para o discurso jornalístico, portanto, é de interesse controlar o efeito de sentido. Apesar da existência do aclamado poder da imagem, mesmo da forte imagem-sintoma, ela "precisa da palavra para ser interpretada" - isto é, para que funcione no discurso jornalístico, ela precisa ser traduzida, "essencializada"; a palavra precisa trabalhar como fator de ancoragem (CHARAUDEAU, 2009, p. 78), e assim funciona, como qualquer frase e palavra, em argumento de um discurso.

\section{A imagem como gerúndio}

Um caso exemplar que extrapolou o âmbito da imprensa e gerou comoção social movente foi feito por Richard Drew durante o atentado ao World Trade Center em setembro de 2001. Uma de suas fotografias foi publicada na página 7 do New York Times do dia 12 de setembro de 2001. Ela ficou conhecida como The Falling Man devido a um artigo publicado na revista Esquire dois anos depois (JUNOD, 2003).

Dentre as várias fotos da série de Drew, esta se destaca pelo forte balanço geométrico, poder de síntese (tudo à direita é a Torre Sul, tudo à esquerda é a Torre Norte) e presença do flagrante ao instante-surpresa, cumprindo à risca os critérios mais reiterados do fotojornalismo. Essa fotografia foi publicada uma única vez por vários jornais logo após o atentado e, depois de algum tempo, nunca mais se falou dela - até a internet recuperá-la (CAUCHON; MOORE, 2002; JUNOD, 2003; LINFIELD, 2011). A polêmica ao redor dessa imagem se deve ao tabu envolvendo a publicização do suicídio e ao forte trauma gerado na sociedade estado-unidense. $\mathrm{O}$ acontecimento foi tão marcante que os jornais que se atreveram a contar a porcentagem de mortos que pularam das torres foram detratados. Até hoje não se tem a conta exata. Durante anos, os jornais precisaram se defender de acusações de que estariam explorando a tragédia, tirando a dignidade das vítimas e invadindo sua privacidade (JUNOD, 2003) ${ }^{8}$.

Impossibilitadas de acederem a qualquer possibilidade de resgate, algumas vítimas do atentado pularam dos prédios e ampla foi o debate sobre considerá-los ou não suicidas. Frente à impossibilidade de escolha entre diferentes riscos de morte, as vítimas foram nomeadas durante algum tempo pela imprensa como “jumpers". Como explica Linfield (2011, s/p, tradução nossa'), "aqueles presos nas Torres tinham apenas duas escolhas - saltar para a morte ou ser incinerados - o que significa dizer que não tinham escolha alguma. Moralizar qualquer 'escolha'- desprezar alguém como covarde e valorizar o outro como heroico - é entender mal ambos”. Oficialmente nenhuma das vítimas fatais do 11/9 foi considerada suicida, mas víti-

8 Logo após o atentado, um repórter do jornal canadense The Globe and Mail foi incumbido da funesta tarefa de identificar o homem da foto (CHENEY, 2001). Na reportagem de grande repercussão da Esquire, Junod (2003) conta a história da investigação que chegou à possível identificação do Falling Man. Apesar de comentar criticamente a atitude editorial canadense, a reportagem de Junod (2003) também investe na nomeação de um segundo sujeito. A investigação de Cheney (2001) se deparou com forte resistência por parte da família da possível vítima para colaborar com o reconhecimento do homem na foto, pois, para eles, era impossível pensar no pai como um suicida por ferir valores religiosos, o que acabou por produzir, além do sofrimento da perda, uma série de constrangimentos sociais (JUNOD, 2003).

9 No original, "Those trapped in the Towers had only two choices-to jump to their deaths or to be incinerated - which is to say they had no choice at all. To moralize either "choice" - to despise one as cowardly and valorize the other as heroic - is to misunderstand both.." 
ma de traumatismo decorrente de queda, conforme o Departamento de Polícia de Manhattan (LEONARD, 2011). Mesmo assim, a mudança de nomeação oficial e a instauração de um novo discurso público sobre as mortes não foi o bastante para afastar a ideia do suicídio e a sua visualização (gerada pelas filmagens e fotografias, principalmente esta) e obliterar o sofrimento das famílias (JUNOD, 2003).

Por mais que se possa considerar uma série de fatores relacionados à aceitação das narrativas sobre o discurso na imprensa, vamos nos atentar aqui para a relação que a censura dessa fotografia tem com a imagem que produz. A proibição de publicação dessa fotografia pode ser compreendida como uma das séries de procedimentos que em alguns momentos da história das imagens protegiam as representações (estátuas, pinturas) dos olhares mundanos - e assim nos protegiam também, de sermos "olhados" por essas imagens (DEBRAY, 1993). Didi-Huberman (2010) se utiliza da fábula joyciana de Ulisses para ilustrar a ideia de que a imagem não se resume ao universo do que se vê, mas está relacionada a todo o espectro do sensível. Pensar sobre "uma imagem que nos olha" é colocar em questão qualquer momento em que uma imagem se impõe (DIDI-HUBERMAN, 2010) - quer seja na câmara mortuária de seu exemplo, quer seja no homem que cai do prédio em chamas. A imagem nos olha porque provoca em nós a invasão de um universo sensível, a imposição de uma sublimidade, poderíamos dizer, uma experiência estética do sublime ${ }^{10}$.

Cada visita do olhar à fotografia do Falling Man faz o terror ser revivido. Esse gatilho proporcionado pela fotografia se dá devido ao seu poder de reconstrução do tempo, pois talvez “seja próprio [dela] mudar o passado em presente/futuro (BARROS, 2017, p. 8)". Uma fotografia está sempre acontecendo, cada vez que é novamente vista. A "presentificação da experiência”, para pensar a partir perspectiva da imagem, é mais importante que o noema "isso foi" de Barthes (1984), tomado como característica incontornável da fotografia e seguindo a perspectiva do discurso. A interpretação é sincrônica ao signo e a decodificação nos faz aderir ao tempo presente que exige uma ação diante do objeto a ser dotado de significação (BARROS, 2017), enquanto o "isso foi" instaura o passado da fotografia. O tempo opera paradoxalmente, pois o passado se torna presente todas as vezes que a fotografia nos faz estar na presença do morto. Essa sobreposição de tempos presente na fotografia nos leva à ideia do "presente eterno" do mito (BARROS, 2017).

A função memorativa que Warburg quis reconduzir às imagens da cultura ocidental (DIDI-HUBERMAN, 2013, p. 389) se dá nessa duplicidade de sentido que o tempo dá à memória: o tempo cronológico e o tempo da oportunidade. Se de um lado o tempo cronológico ancora os eventos do cotidiano num roteiro de acontecimentos ordenados, garantindo a sobrevivência iconográfica dos instantes (pensando na tecnologia fotográfica), permite as representações, as materializações da imagem em discurso visual, por outro lado, o tempo cairológico, esse que não se pode contar, que não obedece à passagem linear do tempo, ele é a condição que permite à imagem voltar a acontecer mesmo que seu evento original já tenha acontecido. Em outros momentos, é ele que dá condição para que aconteçam imagens que nunca tiveram lugar nos eventos cotidianos - por exemplo, as ficções criadas pela arte ou as narrativas do tempo sagrado, como a mitologia.

10 Neste caso, não o kantiano, pois esse seria novamente testemunha do retorno da razão, reforçada por compreender-se como única capaz de nomear o"sublime". 
Segundo Agamben (2012, p. 21), o assombro que a imagem nos provoca se deve ao fato de que, quando simbólicas, elas estão "carregadas de tempo", sofrem de "saturação cairológica". É a inscrição desse tempo dentro da imagem que, segundo ele, nos permite considerar uma "vida das imagens". Seguindo essa ideia, a imagem está filiada à mitologia de Kairós justamente porque não se submete à cronologia dos eventos - nem mesmo à cronologia obrigatória do discurso verbal, que lhe impõe outra lógica operativa, tal como a casuística, e possibilita à imagem encaixar-se como argumento de outra ideia. A narrativa mitológica é uma história que faz sentido através de imagens. Num arranjo desorganizado casuística e cronologicamente, não sabemos quem veio antes ou depois: o universo, onde nasceram as musas, ou as próprias musas, que contam a história do surgimento do universo (TORRANO, 2012)? A contação mítica evidencia um funcionamento do sentido que não cabe no pensamento lógico-dedutivo, e, assim, materializando o modo de funcionamento da imagem.

\section{Imagem como queda do argumento}

Aliado a esta noção de imagem como energia movente, Durand (1998) sugere uma resolução para o impasse: a anterioridade ontológica da imagem frente ao conceito, uma das "grandes resistências intelectuais" em relação à teoria do imaginário (BARROS; WUNENBURGER, 2015, p. 44). A perspectiva durandiana propõe que:
(...) o sentido próprio (que conduz ao conceito e ao signo ade- quado) é apenas um caso particular do sentido figurado, isto é, é apenas um símbolo restrito. (...) não existe corte entre o racio- nal e o imaginário, não sendo o racionalismo, entre outras coi- sas, mais o que uma estrutura polarizante particular do campo das imagens (DURAND, 1995, p. 75).

Tentando pensar, então, o rastro de atuação das imagens, Durand (1995) interliga as imagens mais complexas e indiscerníveis do nosso inconsciente (arquétipos para Jung, schème para Durand) até as representações visuais da esfera do enunciado - onde estão a fotografia e outras manifestações da ordem do discurso visual (BARROS, 2013, 2015) -, chamando isso de trajeto antropológico ou trajeto de sentido. Ao longo do tempo, enquanto as materialidades da ordem do discurso se atualizam, as imagens que os animam permanecem mais ou menos semelhantes.

O poder revelador da imagem é uma característica que define, de vez, a fronteira entre elas e as representações visuais. A imagem precisa de um território para acontecer; mas somente uma parte dela se territorializa, permanecendo o sublime a condição para estar na presença de seu sentido. O tempo, então, se manifesta em símbolos de animalidade, da obscuridade e da decadência (DURAND, 1997). As histórias da mitologia, na proposta da metodologia do imaginário (DURAND, 1997) podem servir como pistas para a relação entre imagens num estado anterior à depuração necessária para o cogito.

Esse circuito, não só de afetos, mas mobilizado pelas disposições do sistema imaginário humano é o que animam de sentido as fotografias para as quais olhamos, na tentativa de "tentar ler o que não está escrito" (DUARTE, SEVERIEN, 2018, p. 220), deixando explícito que as experiências estética e simbólica não estão resumidas à face literal ou representacional de uma 
imagem. Se a retórica e a razão ilustrada elaboram uma rebuscada maiêutica, a imagem, por sua vez, muito provoca e nada conclui para um sentido fora de si. Nesse caso, a imagem torna-se “imagem de", já é necessário um predicado: imagem técnica, fotográfica, iconográfica ${ }^{11}$.

Se "o acesso ao pensamento simbólico não se faz por significação" (DUARTE; SEVERIEN, 2018, p. 22), dado que tomar a imagem como signo é objetificá-la, tratando somente da sua parte representativa, como se daria o acesso ao pensamento por imagem? Devemos compreender o imaginário não como um conjunto de imagens, mas um conjunto e sua lógica organizativa. É nesse sentido que seguimos com Thomas - conforme citado por Barros (2016) - a ideia de pensar o imaginário como um sistema. Podemos avançar e propor tomar o sistema do imaginário antropológico (DURAND, 1997) como uma sistematização do pensamento por imagem.

Sendo poucos os vínculos indexicais que nos informam sobre o atentando ou o prédio em chamas, nos valemos do outro conhecimento de experiência pra animar a fotografia de sentido, o nosso capital simbólico. Poderíamos pensar aquela sublimidade como a instauração dessa imagem - a saber, a criação de um simbólico que permite que ela se manifeste. Isso porque, nessa compreensão de imaginário, o simbólico não é adjetivo, mas condição para o acontecimento da imagem (BARROS; WUNENBURGER, 2015).

O medo da queda é motivador de um universo simbólico de angústia (DURAND, 1997). Na esteira do princípio semântico do isomorfismo das imagens de Bachelard (1998), Durand (1997) avança no pensamento sobre os símbolos entrelaçando a experiência da gravidade que puxa nosso corpo em direção ao centro do mundo com a resistência ao movimento dos nossos pés, que, bem contrabalançada, é justamente o que nos permite caminhar. Assim se dá a relação entre a queda e a temporalidade, pois é o movimento para baixo que condensa simbolicamente a passagem incontornável do tempo. É a angústia proporcionada pela imagem simbólica da queda que nos revela a consciência da passagem do tempo.

Em Falling Man, tanto quanto em outras representações visuais pungentes, vemos a marca do paradoxo. Em termos de representação visual, é mesmo a ideia de um "brutal paradoxo" (DUARTE, SEVERIEN, 2018, p. 209) é o que dá a ver a fórmula pática - nos termos de Warburg -, a pungente simbólica - nos termos do imaginário durandiano. Essa fórmula, no entanto, está mais ligada a um gesto do que a uma representação fixa: é isso que faz possível estabelecermos uma relação entre Falling Man e o Monge em chamas, como no exemplo de Duarte e Severien (2018). Poderíamos pensar que essa fórmula, do corpo-quase-morto, está presente não somente nessas fotografias, mas talvez seja a fórmula pática de toda fotografia. Por repercutir eternamente o instante passado, a fotografia sempre nos coloca diante do corpo morto-vivo. No entanto, o paradoxo em vez de estar presente na imagem de maneira quase literal (o corpo caindo, num gerúndio eterno e ao mesmo tempo fulminante), se instaura quando olhamos para ela: o corpo de ontem está aqui hoje. É com esse susto do re-acontecimento que Barthes (1984) lembra com saudade da mãe no jardim de inverno e que Didi-Huberman (2010) se assusta com as máscaras que parecem olhar para ele. Como fala o autor da reportagem da Esquire, "há algo de quase rebelde em sua postura" que "decide seguir em frente" diante da morte (JUNOD, 2003,

11 Na introdução de sua tese de doutorado, Durand (1997) cita indiretamente, sem nomeá-los, Blaise Pascal (ao pontuar que é dele a concepção de que a imagem é a “louca da casa”) e René Descartes (ao afirmar que a imagem é a "senhora do erro e da falsidade"). 
tradução nossa ${ }^{12}$ ).

É mantendo a mesma operação paradoxal de representação e de tempo que a imagem da catástrofe tanto nos atrai e nos repulsa. Instauradas num regime de tempo cairológico, as imagens necessitam de um território para se realizarem. Territorializadas (manifestas, enunciadas, em formas plásticas definíveis) em parte, o resto da experiência da imagem se dá a partir da experiência estética que ela provoca. Talvez o tamanho desse horror seja a causa da resposta simbólica produzida pelo irresistível esforço das reportagens (CHENEY, 2001, JUNOD, 2003) em nomear a vítima fotografada e assim, quem sabe, por pessoalizá-lo e dá-lo dignidade póstuma (como tradicionalmente se faz na reportagem jornalística humanizadora), ao mesmo tempo, garantir o seu afastamento de nós - nomeado, ele é um “outro absoluto", como explica Rancière (2012). Por vezes, pelo contrário, visualizar materialmente a catástrofe a territorializa longe de nós ${ }^{13}$. É quase como se, por fazermos essa imagem de queda constante receber, em uma legenda, um nome e um sobrenome, fazemos com que a experiência simbólica retorne à esfera do discurso visual e, assim, diminua seu poder sobre nós.

A censura relacionada à publicação da fotografia do dia 11 de setembro provavelmente esteja relacionada a esse poder revelador, no sentido de consciência, daquilo que a imagem nos ajuda a ver - neste caso, a certeza da falibilidade materializada pela imagem simbólica da queda. Essas são imagens que não queremos ver - ou que não queremos que nos vejam, pois assim podem se realizar.

São inúmeros os mitos que terminam catastroficamente esmagados pela queda e poderíamos lembrar-nos de um deles: Atlas, "heroi da luta pela verticalidade" (DURAND, 1997, p. 113). O interessante de frisar a respeito do Atlas de Warburg é esse desprendimento (literal e metafórico) do lugar das imagens: as fotografias não estavam presas aos painéis e poderiam ser recombinadas. O mérito do Atlas, portanto, é expor de que forma as imagens sobrevivem e se recombinam no nosso pensamento - podendo ser jogadas de um lado para o outro, gerando novas recombinações e "quadros", sínteses, conclusões, descobertas, conhecimentos - sem com isso perderem a plasticidade que lhes é intrínseca, ou seja, a mobilidade e a infidelidade que é sua característica própria. Não é por outro motivo que, para a tradição filosófica aristotélica, a imagem é inimiga da razão, pois ela é inconstante, não sucumbe ao epitáfio do significado próprio, e permanece eternamente no jogo do sentido figurado.

Para Didi-Huberman (2013), a montagem materializa o próprio pensamento de Warburg e, poderíamos dizer, das imagens. No Atlas do pensador alemão, cujas pranchas pretas conduzem à formação de um "quadro", de um "sentido combinatório" (DIDI-HUBERMAN, 2013, p. 385), os temas se agrupam de maneira pouco tradicional e estão prontos para serem constantemente recombinados - o que nos parece uma metáfora interessante para compreen-

12 No original, "There is something almost rebellious in the man's posture, as though once faced with the inevitability of death, he decided to get on with it; as though he were a missile, a spear, bent on attaining his own end".

13 Quando os jornais noticiavam a chegada de um tsunami no litoral do Japão em 2011, os internautas já procuravam no Google os termos "tsunami" e "Japão", como se esperassem poder ver ao vivo o desastre (VIDAL, 2016, p. 46). O contrato de comunicação com o jornalismo parece ter sido o bastante para que o público acreditasse na informação da vinda de uma onda gigante, mas não o bastante para crer que a tragédia realmente aconteceria. Para crer de verdade era preciso vê-la e, se possível, antes. 
der como se dá um pensamento por imagem. Se o pensamento permanecer dentro do espectro de funcionamento das imagens, vai conduzir a um resultado sinóptico (DIDI-HUBERMAN, 2013, p. 386), impassível de conclusão, de fechamento, de significação, mas, potência movente de uma energia de sentido que só funciona à medida que provoca.

\section{Considerações finais: cair junto}

Frente à complexidade crescente de pensar sobre as imagens da nossa civilização, nos parece necessário atentar para os momentos em que alguns acontecimentos irrompem da planície do cotidiano em forma de imagem - e, para esse mister, poucas coisas se tornam tão atraentes quando eventos noticiados, visto que a irrupção do comum é o grande valor notícia por definição.

Os pontos levantados pela perspectiva do discurso visual são certamente decisivos para a compreensão a respeito de como se forma o sentido na fotografia. A perspectiva encara a imagem como partícipe no argumento do discurso jornalístico. Está se falando então de sua faceta material, manipulável, a parte da imagem que acontece fora de nós - ou seja, outra que não a faceta bastante incensada pela discussão sobre natureza icônica ou indicial, comum na teoria da fotografia. Essas são as imagens “já vistas” que nos ajudam a decodificar imagens-sintoma, tanto quanto outros discursos verbais nos ajudam na mesma tarefa através da palavra (seu fator de ancoragem). Para tratar a imagem como elemento mobilizador de um discurso visual é preciso, pois, obedecer a duas premissas: tratar a imagem como signo e tomar o sujeito que a produz ou a enxerga como ente capaz de mobilizá-la de maneira consciente.

No entanto, quando o funcionamento da imagem entra na equação do sentido provocado por uma fotografia, sua presença se impõe à revelia dos discursos que naturalmente concorrem para alcançar um estado de normatização. $O$ fato de a imagem visual pertencer ao âmbito da representação nos faz pensar nas importantes características sígnicas que operam na formação de sentido da fotografia. Mas o acontecimento da sublimidade escapa de sua ingerência - mesmo que tenha sido, sim, provocado por ela, a representação figurativa tradicional e nossos códigos de leitura icônica e indicial. Para refletir sobre o caso citado, acontecimento que irrompem da fotografia do discurso jornalístico, é preciso que enfoquemos também nos valores e modos de funcionamento específicos da imagem.

Dar à imagem o mesmo valor discursivo que do texto não é fazê-la subir de nível em termos de potência produtora de sentido, mas, sim, submetê-la à condição de partícipe de uma teoria do conhecimento que precisa estar atenta às regras do pensamento lógico-causal. A imagem pode operar como elemento discursivo não somente porque tem tanto poder simbólico quanto o texto, mas porque ela é tão plástica na sua forma de apresentação e o simbólico é tão dinâmico no seu funcionamento, a ponto de simular o processo de produção de sentido do texto e nos fazer crer que lidar com ela no modo racional e discursivo seja o bastante. Como vimos, a censura à imagem da queda e a correção do discurso a respeito dos jumpers/suicidas não foi o bastante para apagar o trauma gerado pela experiência estética e de consciência catalisadas por essa imagem. Propomos que, para um pensamento por imagem, fosse produtivo inverter os termos: não colocarmos a imagem em pé de igualdade na mobilização do sentido tanto quanto o verbo, mas evidenciar que a possibilidade de o verbo mobilizar sentido seja uma capacidade 
emuladora do funcionamento da imagem, um esforço anacrônico de encontro sígnico dentre a diversidade de sincronias que a imagem permite.

Pensar a existência da imagem como categoria extraordinária do cogito ilustrado nos permite incluir outros sujeitos na fabricação desses sentidos. Se os discursos são criados pelos que conhecem e jogam com as regras da enunciação, a imagem, por oposição, não é atividade exclusiva da mente ilustrada. É também de posse dos iletrados a produção de imagens, por mais que insistamos em reduzir o aspecto de discussão da teoria da imagem a exemplos da arte canônica - quase sempre europeia. Nada nos ensinou o sofrimento que aprendemos a perceber através do índice do gesto nas fotografias. O conhecimento da lei da gravidade - ou do nome da vítima - não é o bastante para encerrarmos o acontecimento da imagem do homem que cai do World Trade Center. À revelia dos códigos que competem por dominá-lo, ele continua caindo, como um Ícaro perpétuo, revelador da megalomania humana, que cresce proporcionalmente ao tamanho do seu império sobre a natureza. A elaboração da enunciação a respeito desses sentidos já pertence a outra esfera do pensamento, quando a imagem se transforma em signo e torna-se, por isso, matéria de operação do código e da linguagem - como estamos fazendo aqui. Mas só estamos podendo fazê-las, as elucubrações intelectuais, porque certa experiência despertou a potência desse sentido, que, agora, luta por transformar-se em algo comunicável, na tarefa de materializar-se em enunciado, de abolir a angústia da presença dessa imagem, de fazer o homem parar de cair, de dar nome às coisas, de cessar o movimento assustador do mundo.

Essa fotografia e outras imagens do atentado de 11/9 ajudaram a transformar esse acontecimento midiático também em acontecimento imagético. A censura quase voluntária dessa imagem reflete uma operação discursiva de respeito às vítimas, mas também a resposta quase protetora que proíbe que essa imagem nos veja, e assim impeça que a imagem da tragédia e do irrevogável destino da morte nos tome de salto. Debruçar-nos por sobre a angústia que nos promove as imagens é garantir-lhes a sobrevivência em relação ao domínio do signo. O esforço para compreender o inquebrantável dinamismo das imagens nos garante não passar ao largo dos momentos de acontecimento do sublime. Ainda, atentos à presença da força movente da imagem, podemos dispor dela como gatilho para mobilizar o raciocínio e evitar que permaneçamos talvez controlados por ela. Ignorar o poder que exercem sobre nós as imagens é correr o risco de acordar o cão de Hades. Orfeu é quem possui a lira unicamente capaz de adormecer o monstro Cérbero, o nosso "inferno interior", marca memorialística do "terror da morte" (BRANDÃO, 1986, p. 243). Ele desce ao inferno para resgatar sua amada Eurídice morta pela mordida de uma cobra, sucumbindo à imersão de uma imagem. De alguma maneira, a história de Orfeu nos lembra a inescapável condição de solitude da alma humana, à qual só a imagem pode fazer companhia.

A longa reportagem da Esquire (JUNOD, 2003) encerra com uma reflexão que reconhece o tamanho do horror que essa imagem nos proporciona: a única certeza a respeito da história dessa fotografia é que durante todo esse tempo, sempre soubemos quem era o homem caindo. Adicionamos a resposta eclipsada retoricamente pela matéria: The Falling Man somos todos nós. 


\section{Referências}

AGAMBEN, Giorgio. Ninfas. São Paulo: Hedra, 2012.

ALLOA, Emmanuel. Introdução: Entre a transparência e a opacidade - o que a imagem dá a pensar. In: ALLOA, Emmanuel (Org.). Pensar a imagem. Belo Horizonte: Autêntica, p. 7-19, 2015.

BACHELARD, G. A água e os sonhos. São Paulo: Martins Fontes, 1998.

BARROS, Ana Taís Martins Portanova. O imaginário e a hipostasia da Comunicação. Comunicação, Mídia e Consumo, São Paulo, v. 10, p. 13-29, 2013.

BARROS, Ana Taís Martins Portanova. A fotografia como narrativa mítica. In: XXXVIII Encontro Anual da Compós, 2015, Rio de Janeiro. Anais... São Paulo: UFRJ, 2015.

BARROS, Ana Taís Martins Portanova; WUNENBURGER, Jean-Jacques. A fotografia como catalisador simbólico - Notas para uma hermenêutica da fantástica em imagens técnicas. Intercom - RBCC, São Paulo, v.38, n.2, p. 39-59, 2015.

BARROS, Ana Taís Martins Portanova. Imaginário: da desvalorização estéril à heurística fértil. In: ROSÁRIO, Nísia Martins; SILVA, Alexandre Rocha (Orgs.). Pesquisa, Comunicação, Informação. Porto Alegre: Sulina, 2016, p. 1-23.

BARROS, Ana Taís Martins Portanova. Imagens do passado e do futuro: o papel da fotografia entre memória e projeção. Matrizes, São Paulo, v. 11, n. 1, p. 1-16, 2017.

BARTHES, Roland. A câmara clara. Rio de Janeiro: Nova Fronteira, 1984.

BENETTI, Marcia. O jornalismo como gênero discursivo. Galáxia, São Paulo, n. 15, p. 13-28, 2008.

BRANDÃO, Junito de Souza. Mitologia grega. Volume I. Petrópolis: Vozes, 1986.

CHARAUDEAU, Patrick. A televisão e o 11 de setembro: alguns efeitos do imaginário. Logos, Rio de Janeiro, v. 13, n. 24, p. 1-10, 2006.

CHARAUDEAU, Patrick. Informação, emoção e imaginários a propósito do 11 de setembro de 2001. In: DAYAN, Daniel (org.). O terror espetáculo: terrorismo e televisão. Lisboa: Edições 70, p. 71-86, 2009.

DEBRAY, R. Vida e morte da imagem. Petrópolis: Vozes, 1993.

DIDI-HUBERMAN, Georges. O que vemos, o que nos olha. São Paulo: Editora 34, 2010.

DIDI-HUBERMAN, Georges. A imagem sobrevivente. Rio de Janeiro: Contraponto, 2013.

DUARTE, Eduardo; SEVERIEN, Pedor. A insustentável leveza do deixar de ser. In: ARAUJO, Denize; BARROS, Ana Taís M. P.; CONTRERA, Malena Contrera; ROCHA, Rose de Melo (Eds.). Imag(em)inário. Porto Alegre: Imaginalis/Página 42, p. 207-225, 2018.

DUBOIS, Philippe. O ato fotográfico e outros ensaios. Campinas: Papirus, 2012.

DURAND, Gilbert. A imaginação simbólica. Lisboa: Edições 70, 1995.

DURAND, Gilbert. As estruturas antropológicas do imaginário. São Paulo: Martins Fontes, 1997.

DURAND, Gilbert. O imaginário. Rio de Janeiro: Difel, 1998. 
MACHADO, Arlindo. A ilusão especular. São Paulo: Gustavo Gili, 2015.

PEIRCE, Charles Sanders. Semiótica. 2a ed. São Paulo: Perspectiva, 1990.

PICADO, José Benjamim. Do problema do iconismo à ecologia da representação pictórica: indicações metodológicas para a análise do discurso visual. Contracampo, Rio de Janeiro, v. 9, n. 2, p. 199-220, 2003.

PICADO, José Benjamim. Da iconicidade à plasticidade gráfica do instantâneo: o mistério do testemunho fotográfico da ação. Fronteiras - estudos midiáticos, São Leopoldo, v. 8, n. 2, p. 160-170, 2006.

PICADO, José Benjamim. Do instante ao estado de coisas: formas de estabilidade no discurso visual do fotojornalismo. Significação, n. 31, p. 129-146, 2009.

RANCIÈRE, J. O destino das imagens. Rio de Janeiro: Contraponto, 2012.

SANTOS, Ana Carolina Lima. Realidade e representação: o discurso visual no fotojornalismo. Mediação, Belo Horizonte, v. 9, n. 9, p. 115-128, 2009.

TORRANO, Jaa. O mundo como função de musas. In: HESÍODO. Teogonia. São Paulo: Iluminuras, p. 11-97, 2011.

VIDAL, Bertrand. Orgias midiáticas e morte ao vivo: o evento-catástrofe no inconsciente visual coletivo. Logos, Rio de Janeiro, v. 23, n. 2, p. 41-53, 2016.

Artigos de jornal

CAUCHON. Dennis; MOORE, Martha. Desperation forced a horrific decision. USA Today, 2002. Disponível em: <http://usatoday30.usatoday.com/news/sept11/2002-09-02-jumper_x. htm>. Acesso em: 26 ago. 2018.

CHENEY, Peter. The life and death of Norberto Hernandez. The Globe Mail, 2011. Disponível em: <http://www.theglobeandmail.com/incoming/the-life-and-death-of-norberto-hernandez/ article4153194>. Acesso em: 26 ago. 2018.

JUNOD, Tom. The Falling Man. Esquire. Edição impressa: Set. 2003. Edição online: 9/9/2016. Disponível em: <http://www.esquire.com/news-politics/a48031/the-falling-man-tom-junod>. Acesso em: 26 ago. 2018.

LEONARD, Tom. The 9/11 victims America wants to forget: The 200 jumpers who flung themselves from the Twin Towers who have been 'airbrushed from history'. DailyMail, 11/09/2011. Disponível em: <http://www.dailymail.co.uk/news/article-2035720/9-11-jumpersAmerica-wants-forget-victims-fell-Twin-Towers.html>. Acesso em: 26 ago. 2018.

LINFIELD, Susie. Jumpers - The Encyclopedia of 9/11. New York Mag, 27/08/2011. Disponível em: <http://nymag.com/news/9-11/10th-anniversary/jumpers >. Acesso em: 26 ago. 2018. 


\title{
Sobre as autoras
}

Anelise Angeli de Carli é doutoranda do Programa de Pós-Graduação em Comunicação da Universidade Federal do Rio Grande do Sul, Bolsista CAPES. Mestre em Comunicação e Informação e Bacharel em Comunicação Social pela mesma instituição. Membro do Imaginalis - Grupo de Estudos sobre Comunicação e Imaginário (CNPq/UFRGS), filiado ao Centre International de Recherches sur I'Imaginaire (CRI2i).anelisedecarli@gmail.com

Ana Taís Martins Portanova Barros é Pós-doutora em Filosofia da Imagem pela Université Jean Moulin - Lyon 3, doutora em Ciências da Comunicação pela Universidade de São Paulo. Docente do Programa de Pós-Graduação em Comunicação e do Departamento de Comunicação, Área Fotografia, da Universidade Federal do Rio de Grande do Sul. Líder do Imaginalis - Grupo de Estudos sobre Comunicação e Imaginário (CNPq/UFRGS) e membro do comitê diretor do Centre International de Recherches sur I'Imaginaire (CRI2i).anataismartins@icloud.com

\section{Notes on a thought by image: from visual discourse to the image as fall}

\begin{abstract}
This paper presents a discussion on the notion of image starting with the photograph that became known as The Falling Man, made during the 9/11 attack in New York. This reflection takes the system of the anthropological imaginary as an underlying perspective of the questions about the existence of a thought by image. The text begins by exploring the scope of the perspective of visual discourse and the limits of taking the image as an argument and arrives to point the need to add elements of image theory to discussion in the case of photographs that will become themselves an event.
\end{abstract}

\section{Keywords}

Image. Imaginary. Symbolic imagination. Photography. Aesthetic experience. 